\title{
Comparison of Butyric Acid Leaching Behaviors of Zinc from Three Basic Oxygen Steelmaking Filter Cakes
}

\author{
Jingxiu Wang ${ }^{1}$, Zhe Wang ${ }^{2, *}$, Zhongzhi Zhang ${ }^{3}$ and Guangqing Zhang ${ }^{1}$ \\ 1 School of Mechanical, Materials, Mechatronic and Biomedical Engineering, University of Wollongong, \\ Wollongong, NSW 2522, Australia; jw071@uowmail.edu.au (J.W.); gzhang@uow.edu.au (G.Z.) \\ 2 State Key Laboratory of Advanced Metallurgy, University of Science and Technology Beijing, \\ Beijing 100083, China \\ 3 State Key Laboratory of Heavy Oil Processing, Faculty of Chemical Engineering, \\ China University of Petroleum, Beijing 102249, China; bjzzzhang@163.com \\ * Correspondence: zhewang@ustb.edu.cn; Tel.: +86-010-62334444
}

Received: 19 March 2019; Accepted: 5 April 2019; Published: 7 April 2019

\begin{abstract}
The selective leaching of zinc from three different basic oxygen steelmaking (BOS) filter cakes by butyric acid was investigated to compare the leaching behaviors of zinc and further to establish the correlation of the zinc leaching performances and the chemical compositions. The effects of acid concentration and the acid to solid (L/S) stoichiometric ratio were studied, with different optimal leaching conditions obtained. BOS-1 showed the lowest leachability with only less than 10\% of zinc removed by $0.5 \mathrm{M}$ acid concentration and $90 \%$ of the L/S stoichiometric ratio in $10 \mathrm{~h}$. The best zinc selectivity was achieved with BOS-2 at $51.2 \%$ of zinc leaching efficiency, with only $0.47 \%$ of iron loss under optimal conditions of $1.5 \mathrm{M}$ acid concentration and a $70 \%$ stoichiometric ratio. BOS-3 showed the highest leaching of zinc but the optimal conditions depend on the priority consideration. Using $1.0 \mathrm{M}$ acid and $90 \%$ stoichiometric ratio for $10 \mathrm{~h}$, the leaching efficiency of zinc was $84.6 \%$ with $20 \%$ iron loss. The filter cakes and the leaching residues were characterized. The results indicate different zinc and iron leaching behaviors, which were probably related to the storage conditions, zinc containing phases and the leaching parameters.
\end{abstract}

Keywords: BOS filter cakes; butyric acid; selective leaching; leaching behaviors; zinc; iron

\section{Introduction}

In the iron and steel industry, over 30 million tonnes of dusts are generated each year [1,2]. Basic oxygen furnace steelmaking (BOS) represents about $57 \%$ of the annual steel production worldwide and electric arc furnace (EAF) accounts for $27 \%$, hence more dusts will be produced and this increasing trend is likely to continue [3]. These dusts are categorized as hazardous metallurgical waste in light of the heavy metals contained [4]. BOS plays a key role in steel production where hot metallic iron from blast furnace (BF) and scrap steel is converted to steel $[3,5]$. The BOS dust contains metal oxides, thus zinc mostly exists as $\mathrm{ZnO}$ and $\mathrm{ZnFe}_{2} \mathrm{O}_{4}$ while iron is mainly found as $\mathrm{Fe}, \mathrm{FeO}, \mathrm{Fe}_{2} \mathrm{O}_{3}, \mathrm{Fe}_{3} \mathrm{O}_{4}$ and $\mathrm{ZnFe}_{2} \mathrm{O}_{4}$. The zinc content ranges from $0.5 \%$ to $8 \%$ with $50-80 \%$ of zinc as $\mathrm{ZnO}$ and the rest as $\mathrm{ZnFe}_{2} \mathrm{O}_{4}$. The iron content in the dust varies between $50 \%$ and 75\% [6-9]. Considering its high iron content, BOS dust is potentially a secondary iron resource for recovery. However, direct recycling is hindered by the problematic zinc and therefore BOS dust has to be stored or disposed of in landfills [10-13].

It has been demonstrated that the composition of the steelmaking dust varies widely depending on the quality of the scrap used, the type of steel produced, and the operating and the aging conditions $[14,15]$. EAF dust has a much higher content of non-ferrous metal oxides than BOS dust. The content of carbon in 
the $\mathrm{BF}$ dust is usually higher than that contained in the BOS dust while zinc content is correspondingly 2-6\% lower. Also, BF dust is coarser than BOS dust due to the difference between the processes. It should be noted that the zinc content in EAF dust is the highest among these three steelmaking dusts.

The best way to solve this problem is to selectively remove zinc from such waste materials by using hydrometallurgy methods, which complies with the policy of sustainable development, helps to alleviate furnace damage, reduces the environmental load of stored waste and also reduces the costs of the replacement of raw materials. Considering the lack of selectivity owing to the large amount of iron dissolution produced using inorganic acids, organic acids are preferred due to having no secondary waste, being environmentally benign and showing indications of a potential bioleaching technology. After selective removal of zinc, the waste becomes an excellent iron-bearing material that can be used as a feed component to produce iron and steel $[4,16]$. Hence, it is feasible to selectively remove zinc from the BOS dusts.

It is presumed that zinc leaching from steelmaking dust is related to the fraction of $\mathrm{Zn}$ in the form of $\mathrm{ZnO}$ because $\mathrm{ZnFe}_{2} \mathrm{O}_{4}$ has a very stable spinel structure that is considerably refractory against leaching [17-20]. However, no specific relationship between the leaching efficiency of zinc and the $\mathrm{ZnO}$ fraction has been established. Steer and Griffiths investigated the leaching of zinc from BF slurry with $2.25 \mathrm{wt} . \%$ of $\mathrm{Zn}$ in the form of $\mathrm{ZnO}$ using $1 \mathrm{M}$ prop-2-enoic acid, and $83.1 \%$ of zinc was removed [21]. Kelebek et al. found that the fine fraction of $\mathrm{BOS}$ sludge contained a greater proportion of $\mathrm{ZnFe}_{2} \mathrm{O}_{4}$ than the coarse fraction, and $81 \%$ of zinc removal was achieved for the coarse fraction by leaching with $\mathrm{H}_{2} \mathrm{SO}_{4}$ while only $29.2 \%$ removal was achieved for the fine fraction [7]. It was reported by Vereš et al. that BOS dust contained 9.37 wt. \% zinc with $14.5 \%$ of the total zinc as $\mathrm{ZnFe}_{2} \mathrm{O}_{4}$ and the remaining portion as $\mathrm{ZnO}$, and the zinc extraction was less than $50 \%$ even if the $\mathrm{H}_{2} \mathrm{SO}_{4}$ concentration was increased to $2.0 \mathrm{M}$ at room temperature [22]. Using $\mathrm{H}_{2} \mathrm{SO}_{4}$ to leach zinc from BOS sludge with $2.74 \%$ of $\mathrm{Zn}$, about $10 \%$ of zinc was removed at room temperature and low acid concentration $(0.1$ and $0.2 \mathrm{M}$ ) since only $\mathrm{Zn}$ in $\mathrm{ZnO}$ was leached out. However, $\mathrm{Zn}$ in $\mathrm{ZnFe}_{2} \mathrm{O}_{4}$ was further dissolved at higher temperatures and higher concentrations $(1 \mathrm{M})$, giving increased zinc and iron leaching efficiencies over $50 \%$ [11]. So, the characteristics of the steelmaking dusts are closely related to the zinc leaching performance.

Butyric acid $\left(\mathrm{CH}_{3} \mathrm{CH}_{2} \mathrm{CH}_{2} \mathrm{COOH}\right)$, as a 4-carbon short-chain fatty acid, is known to have many applications in the chemical, food, and pharmaceutical industries. It is partially dissociated weak acid, and the stabilization of $\mathrm{CH}_{3} \mathrm{CH}_{2} \mathrm{CH}_{2} \mathrm{COO}^{-}$could potentially alter the extraction capability as follows.

$$
\mathrm{CH}_{3} \mathrm{CH}_{2} \mathrm{CH}_{2} \mathrm{COOH}+\mathrm{H}_{2} \mathrm{O}=\mathrm{CH}_{3} \mathrm{CH}_{2} \mathrm{CH}_{2} \mathrm{COO}^{-}+\mathrm{H}_{3} \mathrm{O}^{+}
$$

In a previous study [23], butyric acid was shown to be highly efficient in selective leaching of zinc over iron from a BOS filter cake. However, each steelmaking dust is unique in terms of the chemical composition and herein it is necessary to study the leaching performances of different steelmaking wastes using butyric acid. This paper compares the leaching behaviors of zinc from three different BOS filter cakes using butyric acid to develop a better understanding of the relations to their chemical, physical, morphological and mineralogical characterization. This is vital to the design of alternative techniques for treating such BOS filter cakes. The optimal leaching conditions for maximum zinc removal and minimum iron removal from the three BOS filter cakes were determined by varying acid concentration and the acid to solid (L/S) stoichiometric ratio. The filter cakes and the corresponding leaching residues were characterized by $\mathrm{X}$-ray fluorescence (XRF), $\mathrm{X}$-ray diffraction $(\mathrm{XRD})$, scanning electron microscopy with energy dispersive $\mathrm{X}$-ray spectrometer (SEM/EDS), thermo-gravimetric/differential scanning calorimetry (TG/DSC). 


\section{Materials and Methods}

\subsection{Materials}

The three different BOS filter cake wastes were collected from a steelwork in Australia, and the details are provided in Table 1. These samples were oven dried, crushed and sieved to 300-500 $\mu \mathrm{m}$ for leaching experiments.

Table 1. The information of the three different BOS filter cake samples.

\begin{tabular}{cccc}
\hline Sample & Storage Time & Pretreatment & Color \\
\hline BOS-1 & Several years & Sintered in Stockpile & Red brown \\
BOS-2 & Half a year & Heated at $130{ }^{\circ} \mathrm{C}$ for 40 days & Shiny black \\
BOS-3 & Within one month & Freshly stored in fridge & Dull black \\
\hline
\end{tabular}

Butyric acid with 99\% purity supplied by Sigma Aldrich, Australia, was used as a leaching reagent. Zinc and iron standard solutions were used for the calibration of inductively coupled plasma-optical emission spectrometry (ICP-OES 710, Agilent, Australia) analysis to determine the concentrations of zinc and iron. The deionized water used for dilution of different acids was purified using a water super-purification apparatus (Milli-Q, Millipore, North Ryde, Australia).

\subsection{Leaching Experiments}

The leaching experiments were performed in $250 \mathrm{~mL}$ conical flasks on a horizontally oscillating shaker (RM2, Ratek, Boronia, Australia) with $120 \mathrm{rpm}$ to stir the samples for $10 \mathrm{~h}$ at ambient temperature. The effects of acid concentration and L/S stoichiometric ratio were investigated in the study. The acid concentrations tested are $0.5,1.0,1.5$, and $2.0 \mathrm{M}$ with the butyric acid solution fixed at $150 \mathrm{~mL}$. At each acid concentration, the 10,30,50, 70 and 90\% of L/S stoichiometric ratio [23] were investigated to express the solid weight added.

The sampling was taking under agitated conditions by removing $1.0 \mathrm{~mL}$ of leaching solution to be diluted to $10 \mathrm{~mL}$ using deionized water and filtered by $0.22-\mu \mathrm{m}$ cellulose nitrate membrane using syringe. Further dilution was made by $2 \%$ nitric acid to appropriate Fe and $\mathrm{Zn}$ concentration ranges for the analysis by ICP-OES. The leaching efficiency was calculated from a mass balance as follows:

$$
\text { Leaching efficiency }(\%)=\frac{\text { Mass of } \mathrm{M} \text { in leachate }}{\text { Mass of } \mathrm{M} \text { in filter cake added into flask }} \times 100
$$

where $\mathrm{M}$ is either $\mathrm{Zn}$ or Fe.

The $\mathrm{pH}$ of the leaching solutions was measured. After leaching, the final solid residues were washed with deionized water, filtered, dried and weighed for further characterization.

\subsection{Characterization of the Filter Cakes and Leaching Residues}

The chemical compositions of the BOS filter cakes were determined by X-ray fluorescence (XRF, AMETEK SPECTRO XEPOS ED-XRF, Kleve, Germany). To avoid loss of zinc when it was melted with fluxing material, all the samples were first heated slowly to $600{ }^{\circ} \mathrm{C}$ in an oxygen stream to remove their carbonaceous matter. The mineralogical compositions of the original filter cakes and leaching residues were analyzed by X-ray diffraction (XRD, GBC MMA, Braeside, Australia). The XRD patterns for quantitative analysis were obtained at $35 \mathrm{kV}$ and $28.5 \mathrm{~mA}$ with monochromated Cu-K $\alpha$ X-ray radiation $(\lambda=1.5406 \AA)$ from $10^{\circ}$ to $142^{\circ}$ at a scanning speed of $0.5^{\circ} / \mathrm{min}$ with a step size of $0.014^{\circ}$. The patterns for qualitative analysis were from $15^{\circ}$ to $85^{\circ}$ at a scanning speed of $1.5^{\circ} / \mathrm{min}$ with a step size of $0.05^{\circ}$. The morphologies were studied by scanning electron microscopy with energy dispersive X-ray spectrometer (SEM/EDS, JSM-6490LV, JEOL, Tokyo, Japan). The thermo-gravimetric (TG) and differential scanning calorimetry (DSC) analysis of the thermal behavior of the filter cake samples was 
performed using the NETZSCH STA 449 F5 Jupiter (Selb, Germany) under air and argon atmospheres. Approximately $100 \mathrm{mg}$ of a sample was loaded in an $\mathrm{Al}_{2} \mathrm{O}_{3}$ crucible on a pan of the microbalance, and scanned in the temperature range of $50-800{ }^{\circ} \mathrm{C}$ at a heating efficiency of $10^{\circ} \mathrm{C} / \mathrm{min}$ and a flow efficiency of $100 \mathrm{~mL} / \mathrm{min}$. An empty pan served as the reference.

\section{Results and Discussion}

\subsection{Characterization of the BOS Filter Cakes}

The chemical compositions of the three BOS filter cakes were listed in Table 2, and similar elements were observed. They mainly contained Fe and $\mathrm{Zn}$ together with small amounts of $\mathrm{Ca}, \mathrm{Mg}$ and $\mathrm{Si}$. Other metals exhibited very low concentrations below $1 \%$. BOS- 1 contained the lowest zinc level at $2.42 \mathrm{wt} . \%$, followed by $6.53 \mathrm{wt} . \%$ in BOS-2, which is approximately half of that in BOS-3 at $13.77 \mathrm{wt} . \%$. The corresponding iron content in the three filter cakes showed insignificant differences at $56.0 \mathrm{wt} . \%$, $56.5 \mathrm{wt} . \%$ and $60.0 \mathrm{wt} . \%$, respectively.

Table 2. The chemical compositions of the three BOS filter cakes (wt.\%) based on the oxide content.

\begin{tabular}{cccc}
\hline Sample & BOS-1 & BOS-2 & BOS-3 \\
\hline $\mathrm{Fe}$ & 56.0 & 56.4 & 60.0 \\
$\mathrm{Zn}$ & 2.42 & 6.52 & 13.8 \\
$\mathrm{Ca}$ & 4.04 & 2.86 & 3.02 \\
$\mathrm{Mg}$ & 1.73 & 1.16 & 0.95 \\
$\mathrm{Si}$ & 0.72 & 0.65 & 1.01 \\
$\mathrm{Al}$ & 0.07 & 0.02 & 0.09 \\
$\mathrm{Mn}$ & 0.83 & 0.67 & 0.61 \\
$\mathrm{Ti}$ & 0.015 & 0.022 & 0.007 \\
$\mathrm{~K}$ & 0.031 & 0.029 & 0.020 \\
$\mathrm{~Pb}$ & 0.096 & 0.085 & 0.387 \\
$\mathrm{Cr}$ & 0.053 & 0.022 & 0.035 \\
$\mathrm{Ni}$ & 0.030 & 0.008 & 0.000 \\
$\mathrm{~V}$ & 0.039 & 0.012 & 0.013 \\
$\mathrm{LOI}{ }^{1}$ & 4.73 & 1.89 & 3.56 \\
\hline \multicolumn{4}{c}{${ }^{1}$ LOI-Loss on Ignition at $1050{ }^{\circ} \mathrm{C}}$.
\end{tabular}

Figure 1 presents the XRD patterns of the three BOS filter cakes. It can be found that zinc existed as $\mathrm{ZnO}$ and $\mathrm{ZnFe}_{2} \mathrm{O}_{4}$ in all the samples, but the contents of zinc in these two compounds varied widely. The quantitative analysis showed that the content of zinc in $\mathrm{ZnO}$ was significantly lower, equal to, while much higher than that in $\mathrm{ZnFe}_{2} \mathrm{O}_{4}$ for BOS-1, BOS-2, and BOS-3, respectively. For iron containing phases, $\mathrm{FeO}, \mathrm{Fe}_{3} \mathrm{O}_{4}$ and $\mathrm{Fe}$ were detected in all these samples but $\mathrm{Fe}_{2} \mathrm{O}_{3}$ was only found in BOS-1. $\mathrm{Fe}_{3} \mathrm{O}_{4}$ and $\mathrm{Fe}_{2} \mathrm{O}_{3}$ were the predominant crystalline phases in BOS-1 while $\mathrm{FeO}$ and Fe were the major iron states in both BOS-2 and BOS-3, indicating that BOS-1 is more oxidized. Calcite was also confirmed in all these three samples.

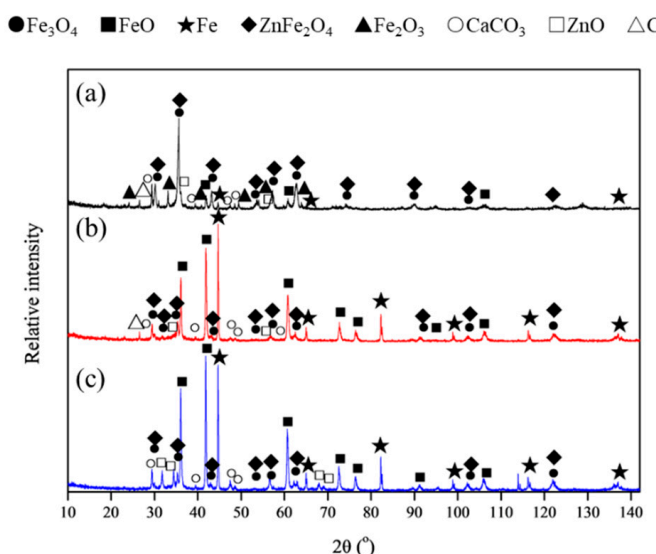

Figure 1. XRD patterns of the three BOS filter cakes: (a) BOS-1; (b) BOS-2; (c) BOS-3. 
Figure 2 presents the morphology of the three BOS filter cakes. All the samples consist of fine grains with various shapes and sizes, but the grain size of BOS-1 is obviously larger than those of BOS-2 and BOS-3. BOS-1 contains non-spherical grains and clusters of submicron grains, but the majority of the grains are $>1 \mu \mathrm{m}$. EDS analysis confirmed the presence of metal oxides that were mainly iron oxides, followed by the oxides of $\mathrm{Zn}, \mathrm{Al}, \mathrm{Ca}$ and $\mathrm{Mg}$. For BOS-2 and BOS-3, the individual grains are predominantly spherical at submicron level, and large grains $>1 \mu \mathrm{m}$ are rare. The fine grains agglomerated together to form a porous structure of the filter cakes which favors the access of acid to zinc in leaching.
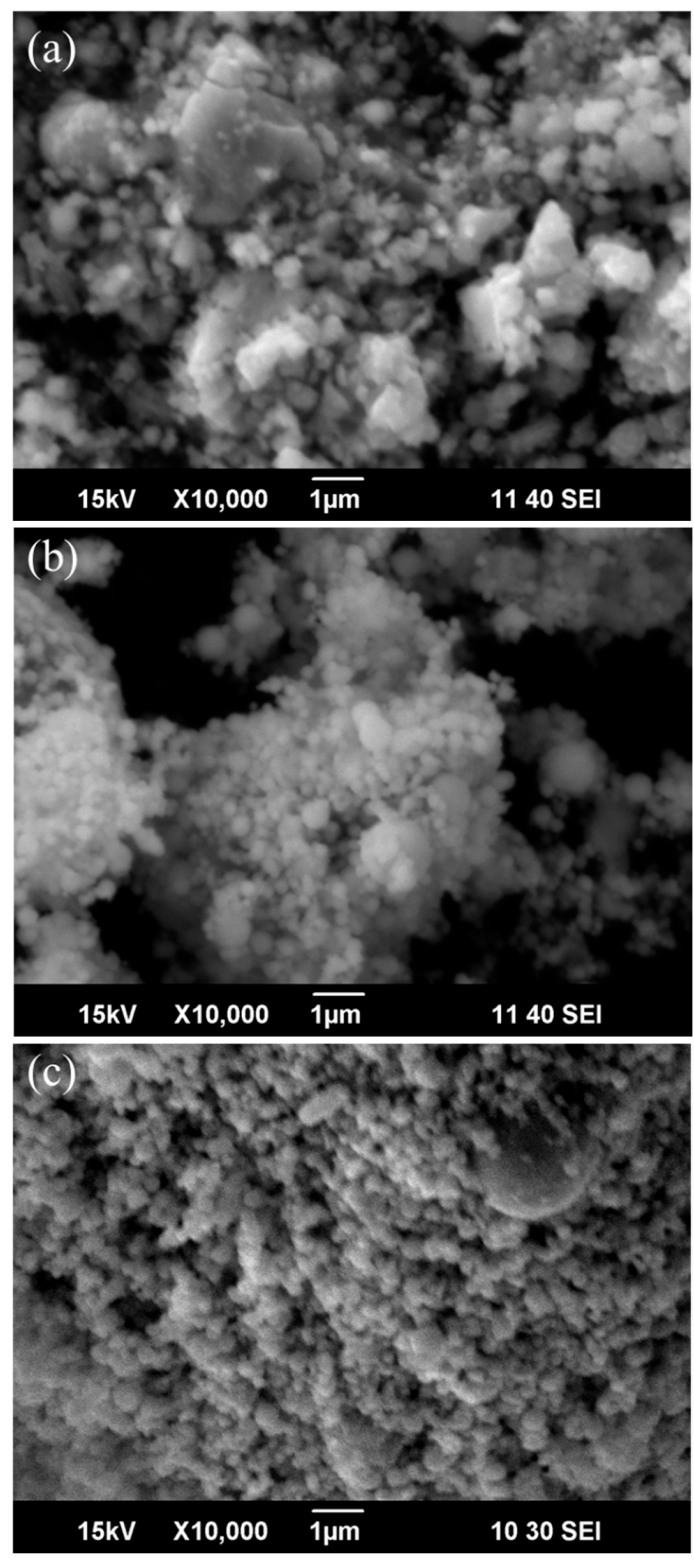

Figure 2. SEM micrographs of the three BOS filter cakes. (a) BOS-1; (b) BOS-2; (c) BOS-3.

Figure 3 presents the TG-DSC curves of the three BOS filter cakes, which were obtained in the temperature range of $50-800{ }^{\circ} \mathrm{C}$ both in air and in argon with a gas flow rate of $100 \mathrm{~mL} / \mathrm{min}$. Overall, the TG patterns of BOS-2 and BOS-3 show similar trends of weight increase in air atmosphere up to $500{ }^{\circ} \mathrm{C}$, while mass loss in argon atmosphere. However, BOS-1 mainly was subjected to a weight loss with increasing temperature in both atmospheres. In air, the weight loss of BOS-1 was $5.15 \%$. For filter cakes BOS-2 and BOS-3, there was $4.4 \%$ and $5.11 \%$ of total weight gain, respectively. The 
results indicated some oxidation and possible combustion reactions for both BOS-2 and BOS-3 with two strong exothermic peaks at about $340^{\circ} \mathrm{C}$ and $430^{\circ} \mathrm{C}$. In argon atmosphere, the absence of free oxygen in the furnace led to no oxidation reactions in contrast to the analysis in air, and hence the mass loss became increasing monotonically as reflected by the TG curves. The weight loss recorded for BOS-1 was $5.96 \%$, followed by $4.44 \%$ for BOS- 2 and $3.36 \%$ for BOS-3.
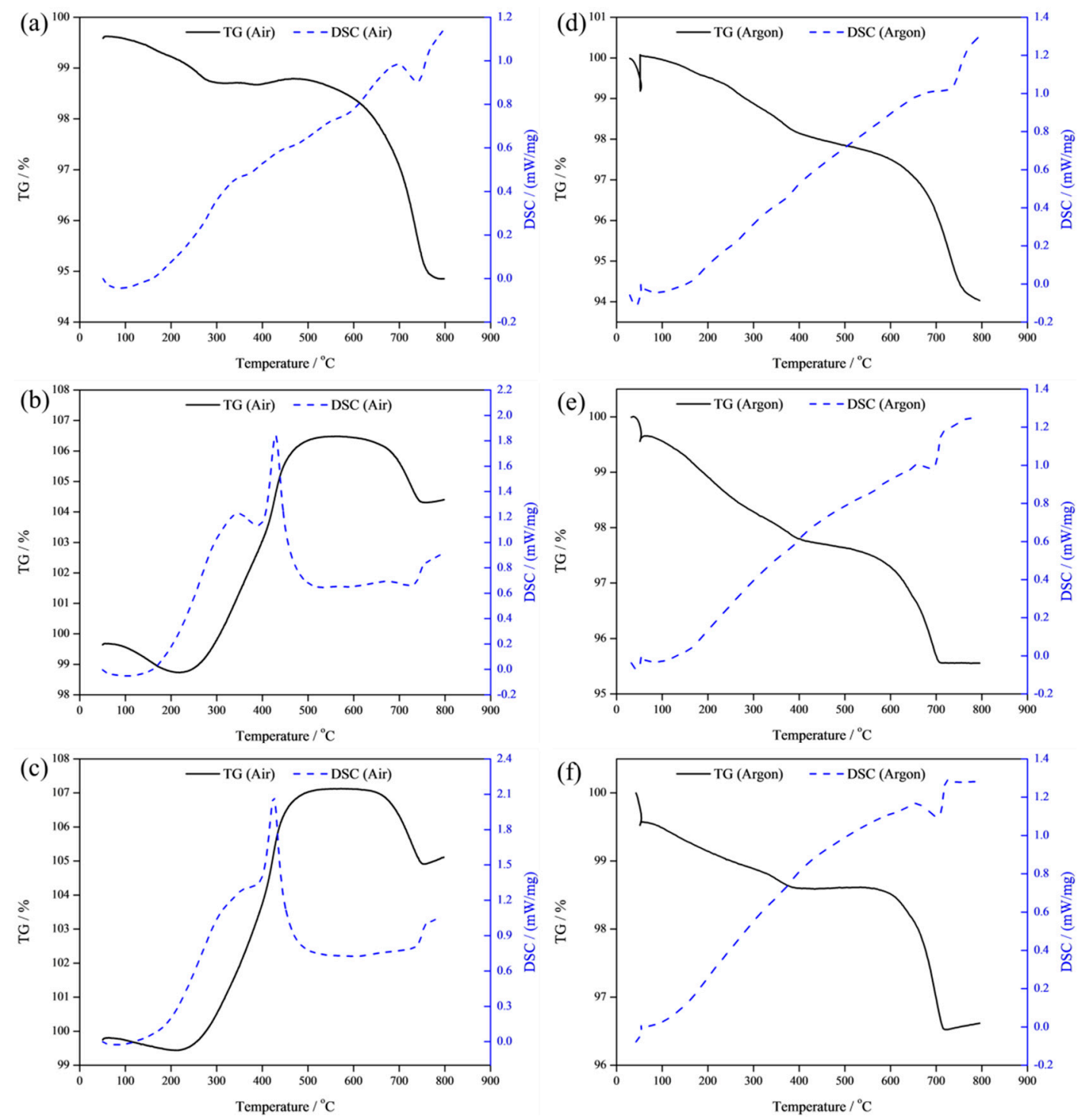

Figure 3. TG-DSC curves of the three BOS filter cakes in air and argon atmospheres: (a) BOS-1, in air; (b) BOS-2, in air; (c) BOS-3, in air; (d) BOS-1, in argon; (e) BOS-2, in argon; (f) BOS-3, in argon.

Figure 4 presents the XRD patterns of the filter cakes subjected to the TG-DSC analysis (reacted samples). The results confirmed that the weight changes are due to oxidation and reduction of the iron and its oxides in the BOS filter cakes. In air, all the three filter cakes are nearly fully oxidized during heating to $800{ }^{\circ} \mathrm{C}$, since $\mathrm{Fe}_{2} \mathrm{O}_{3}$ and $\mathrm{ZnFe}_{2} \mathrm{O}_{4}$ (both containing $\mathrm{Fe}^{3+}$ ) are the dominant phases in the reacted samples as seen in Figure $4 \mathrm{a}-\mathrm{c}$. However, the weight gain resulted from BOS-1 was less than the weight loss caused by the dehydration and dissociation of the calcium carbonate. This led to the total mass loss in air for BOS-1. On the other hand, BOS-2 and BOS-3 are converted mainly to FeO phase in addition to metallic $\mathrm{Fe}$ in the argon atmosphere (Figure 4e,f). The slight difference of mass loss for BOS- 1 in air and argon can be attributed to the oxidation of low contents of $\mathrm{Fe}, \mathrm{FeO}$ and $\mathrm{Fe}_{3} \mathrm{O}_{4}$ to $\mathrm{Fe}_{2} \mathrm{O}_{3}$ as shown in Figure 4a,b [24]. 

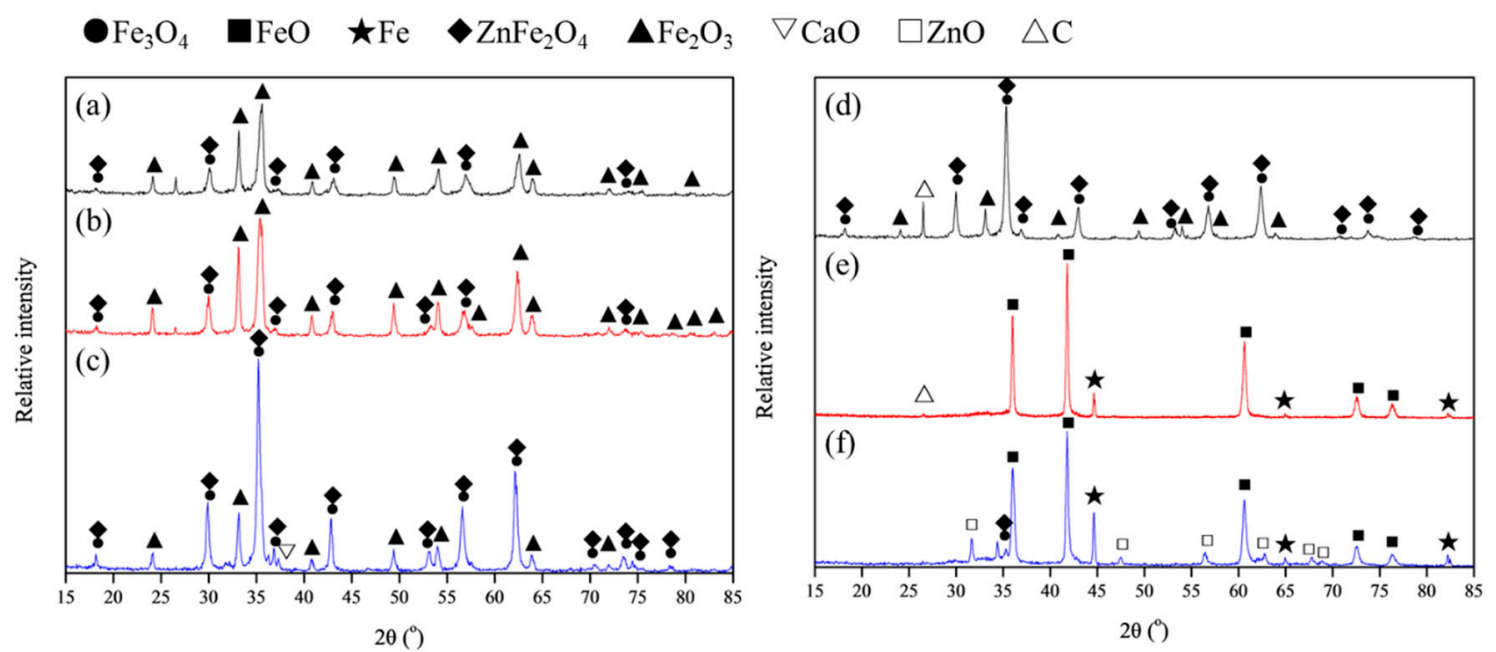

Figure 4. The XRD patterns of the BOS filter cakes subjected to TG-DSC analysis in air and argon atmospheres: (a) BOS-1, in air; (b) BOS-2, in air; (c) BOS-3, in air; (d) BOS-1, in argon; (e) BOS-2, in argon; (f) BOS-3, in argon.

\subsection{The Leaching Performance of the Different BOS Filter Cakes}

The three BOS filter cakes were leached by butyric acid under the same leaching conditions and the corresponding zinc and iron leaching efficiencies were obtained. Figure 5 compares the leaching efficiency of zinc at different L/S stoichiometric ratios and acid concentrations. BOS-3 filter cake shows the highest efficiency, followed by BOS-2, while less than $10 \%$ of zinc was dissolved from BOS-1 at all the above leaching conditions. BOS-3 shows a strong dependence on the L/S stoichiometric ratio, and increasing the ratio caused considerable increase in the leaching efficiency of zinc at all the acid concentrations. However, the acid concentration did not have a significant impact on the zinc leaching efficiency. For BOS-2, the increase in the L/S stoichiometric ratio from $10 \%$ to $50 \%$ increased zinc removal considerably, but further increases did not show an obvious increase in zinc removal. Like BOS-3, acid concentration also had a slight effect on the leaching efficiency. It should be noted that the maximum zinc leaching efficiency was limited at about $55 \%$, and no larger increase can be achieved by increasing acid concentration and L/S stoichiometric ratios. BOS-1 showed no increasing trend at all the leaching conditions, indicating the poorest leaching performance of zinc in butyric acid solution.

Figure 6 shows the iron dissolution from the three BOS filter cakes in relation to L/S stoichiometric ratio at various acid concentrations. Like zinc leaching from BOS-1, iron dissolution was less than $1 \%$ at all the leaching conditions tested. The change pattern of the iron dissolution from BOS-2 was complex. At the low acid concentration of $0.5 \mathrm{M}$, the iron leaching efficiency increased significantly with an increase of the L/S stoichiometric ratio, and up to $30 \%$ of iron was dissolved at the ratio of $90 \%$. Increasing the acid concentration to $1.0 \mathrm{M}$ reduced the iron dissolution dramatically to less than $5 \%$. A further increase in the acid concentration to 1.5 and $2.0 \mathrm{M}$ caused the iron dissolution even below $1 \%$, which seemed to be independent of the $\mathrm{L} / \mathrm{S}$ stoichiometric ratio. It is inferred that acid concentration played a crucial role in controlling the iron dissolution from BOS-2. BOS-3 shows the same leaching behavior of iron with that of zinc, revealing the remarkable effect of the L/S stoichiometric ratio and the small impact of the acid concentration.

It can be concluded that the leaching of BOS-3 filter cake reached the best outcome with butyric acid concentration at $1.0 \mathrm{M}$. Under this concentration, the optimal leaching conditions can be determined for different objectives to achieve as indicated by Supplementary Figure S1. To achieve the maximum zinc removal, a leaching for $10 \mathrm{~h}$ with $\mathrm{L} / \mathrm{S}$ stoichiometric ratio at $90 \%$ can be adopted which can reach $85 \%$ zinc removal and $20 \%$ iron loss. However, a better selectivity of zinc can be attained by decreasing the ratio to $70 \%$ or reducing the leaching time to $2 \mathrm{~h}$. 

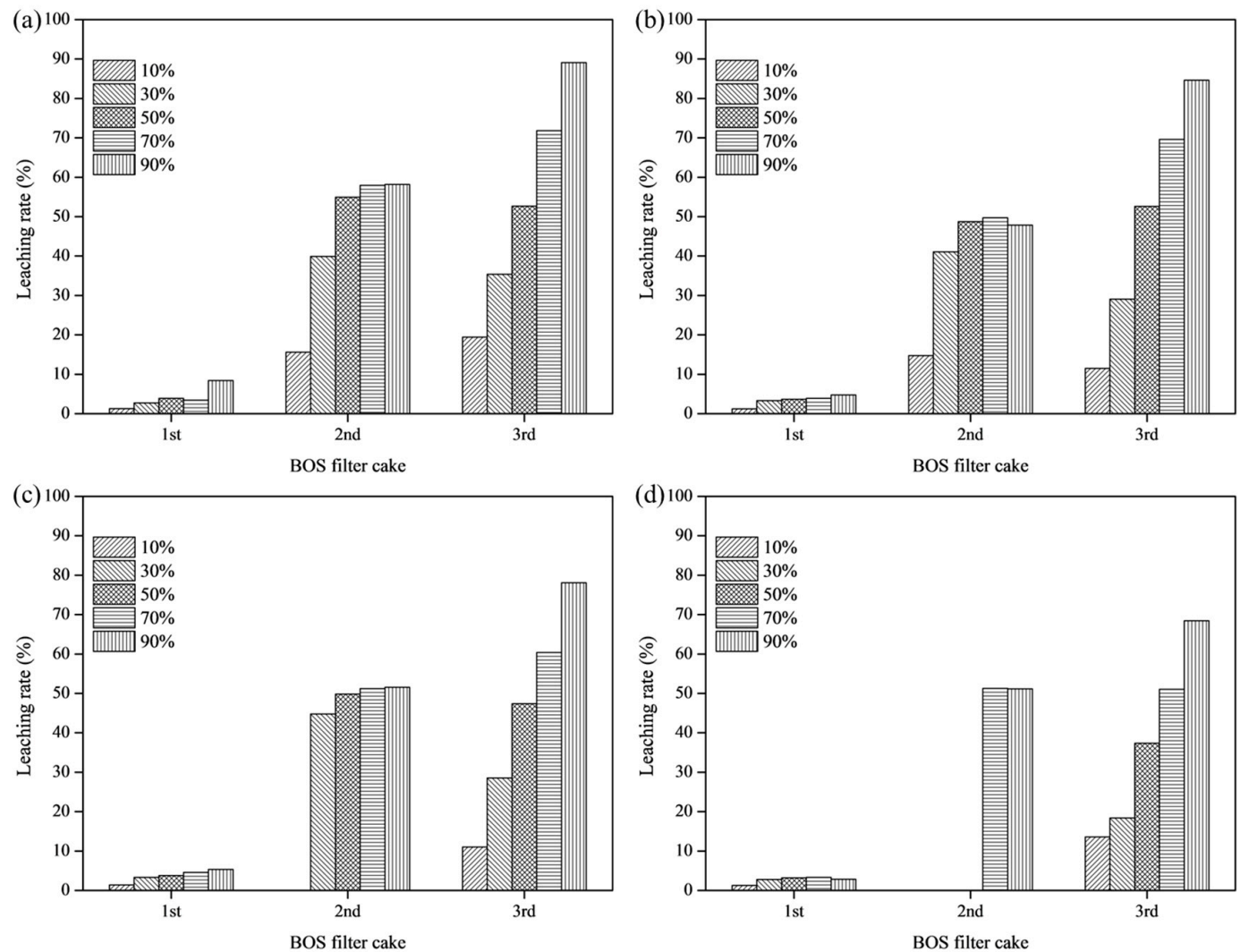

Figure 5. The leaching efficiency of $\mathrm{Zn}$ from three different BOS filter cakes at L/S stoichiometric ratios $10 \%$ to $90 \%$ and acid concentrations (a) $0.5 \mathrm{M}$, (b) $1.0 \mathrm{M}$, (c) $1.5 \mathrm{M}$ and (d) $2.0 \mathrm{M}$.
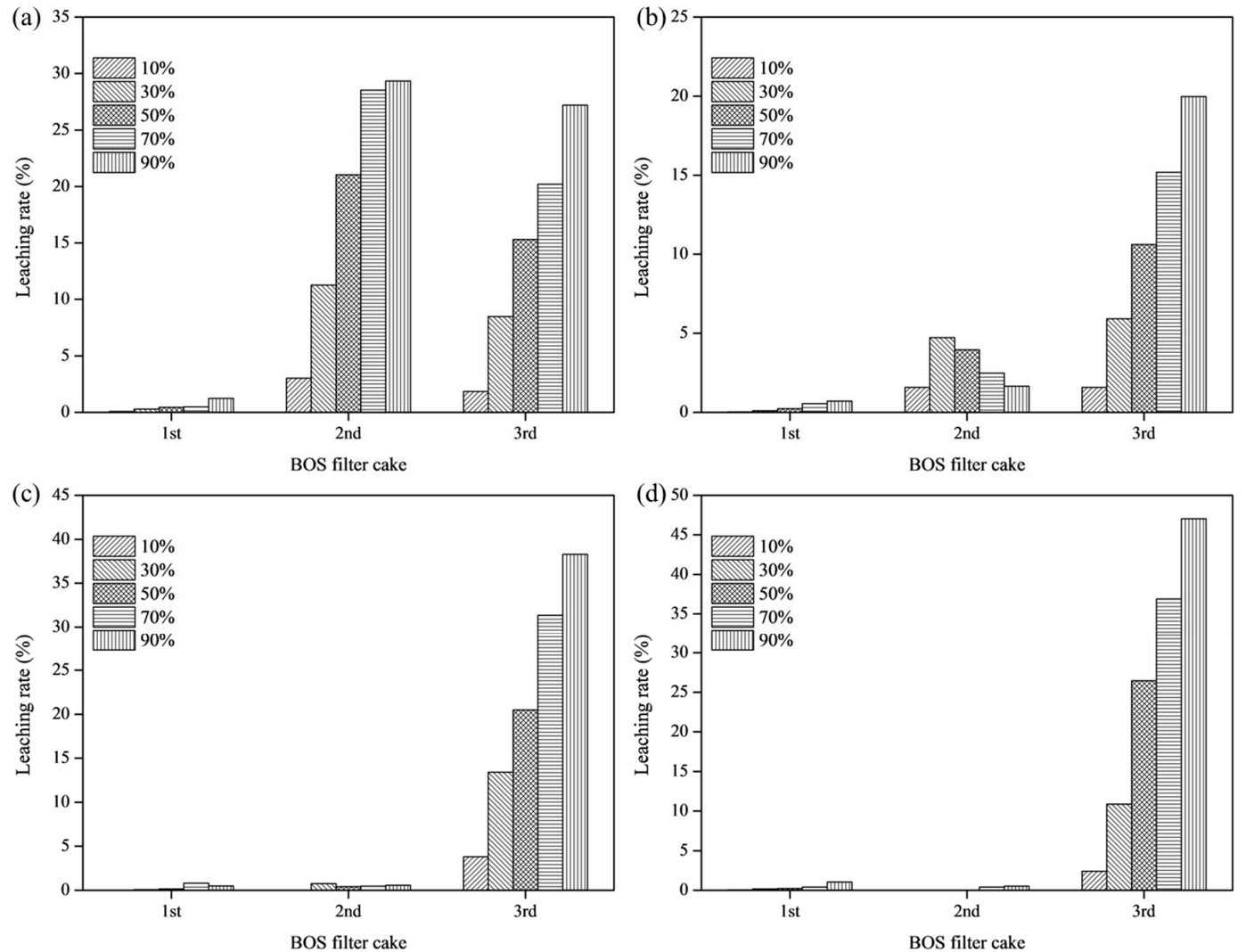

Figure 6. The leaching efficiency of Fe from three different BOS filter cakes at L/S stoichiometric ratio $10 \%$ to $90 \%$ and acid concentration (a) $0.5 \mathrm{M}$, (b) $1.0 \mathrm{M}$, (c) $1.5 \mathrm{M}$ and (d) $2.0 \mathrm{M}$. 
Overall, the three BOS filter cakes showed various leaching behaviors of zinc and iron. BOS-1 showed a poor leachability of zinc and iron in butyric acid solutions, which is likely related to the self-sinter behavior resulting from long term stockpile of the waste, and some exothermic oxidation-sintering reactions probably occurred [25]. The obtained sample generally has stronger physical properties with a harder surface, higher density and strength, and a larger grain size in comparison with the fresh filter cake, which can make the acid leaching very difficult. Another reason is the higher content of zinc in $\mathrm{ZnFe}_{2} \mathrm{O}_{4}$ than that in $\mathrm{ZnO}$ as demonstrated by quantitative XRD analysis, and $\mathrm{ZnFe}_{2} \mathrm{O}_{4}$ was very stable and insoluble in traditional acid leaching process [17-20]. The best leaching selectivity of zinc over iron was achieved from BOS-2, which depends on the increasing acid concentration to form the hydrophobic butyric film adsorbed on Fe-containing phases hindering the leaching of Fe. It was reported that zinc exhibits amphoteric character and is soluble in a wide range of $\mathrm{pH}$ from 0 to 6, while iron dissolution mainly dependent on $\mathrm{pH}$ (see Supplementary Table $\mathrm{S} 1)$. By increasing the acid concentration to form a hydrophobic protective film for the adsorption of butyric acid by iron ions rather than zinc ions, iron dissolution can be effectively limited. However, the maximum zinc leaching can only be reached without the unleachable zinc contained in $\mathrm{ZnFe}_{2} \mathrm{O}_{4}$. In comparison, BOS-3 tended to be most easily dissolved in terms of zinc and iron. This could be ascribed to the adequate storage of this fresh BOS filter cake to avoid the exothermic oxidation reaction in stockpiles causing a higher stability of the zinc phases contained in the leaching material, and the binding force was not strong enough to resist acid leaching. To conclude, the optimum leaching conditions for the selectively leaching of zinc over iron from the three BOS filter cakes, the resulted leaching efficiencies of zinc and iron, and the selectivity as the $\mathrm{Zn} / \mathrm{Fe}$ ratio are summarized in Table 3 (BOS-2 Data from [23]).

Table 3. The optimal conditions and the corresponding leaching efficiencies of the three BOS filter cakes.

\begin{tabular}{cccccc}
\hline \multirow{2}{*}{ Sample } & \multirow{2}{*}{$\begin{array}{c}\text { Zn Removal } \\
\mathbf{( \% )}\end{array}$} & $\begin{array}{c}\text { Fe Removal } \\
(\mathbf{\%})\end{array}$ & $\begin{array}{c}\text { Zn/Fe Ratio } \\
(\boldsymbol{w} / \boldsymbol{w})\end{array}$ & \multicolumn{2}{c}{ Optimal Parameters } \\
\cline { 5 - 6 } & 8.4 & 1.2 & 0.8 & 0.5 & 90 \\
\hline BOS-1 & 51.2 & 0.47 & 12.6 & 1.5 & 70 \\
BOS-2 & 84.6 & 20.0 & 0.5 & 1.0 & 90 \\
BOS-3 & & &
\end{tabular}

\subsection{Characterization of the Leached Residues}

Figure 7 presents the XRD patterns of the leaching residues obtained under the optimal leaching conditions. No obvious change of the phases were observed for the residue of BOS-1 except for the disappearance of $\mathrm{ZnO}$ and some peaks of $\mathrm{Fe}$, and this matched well with the corresponding lower zinc and iron leaching efficiencies. The same phases of $\mathrm{Fe}, \mathrm{FeO}$ and $\mathrm{Fe}_{3} \mathrm{O}_{4}$ were still detected from the residue of BOS-2 due to the $0.47 \%$ iron dissolution. Apparently, the residue of BOS-3 showed remarkable changes of phases and the relative contents. For iron-containing phases, Fe was mostly dissolved while no obvious dissolution of $\mathrm{FeO}$ and $\mathrm{Fe}_{3} \mathrm{O}_{4}$ was observed. The disappearance of $\mathrm{ZnO}$ peaks from all the filter cakes implied that it was completely dissolved, or the remaining amount was below the limit of the detection. As expected, there was insignificant variation of $\mathrm{ZnFe}_{2} \mathrm{O}_{4}$ peaks.

Figure 8 presents the morphology of the corresponding leaching residues and there were some changes in contrast with the original samples. The shape and grain size of the BOS-1 residue are almost the same as before leaching. The EDS analysis also does not show much difference. This corresponds to the low leaching efficiencies of zinc and iron by butyric acid. For the residue of BOS-2, although the morphology generally unchanged after leaching, the overall zinc content appears to be decreased based on the EDS results. Considering that up to $50 \%$ of zinc was removed by leaching with very low loss of iron, it can be recognized that iron oxides forming the basic structure of the filter cake were not affected by the removal of zinc. For the residue of BOS-3, it seems that the fine particles were leached, leaving the residue with relatively coarse grains (comparable to BOS-1) and higher porosity, which is consistent with the high zinc and iron leaching efficiencies. 
$\begin{array}{llllllll}\mathrm{Fe}_{3} \mathrm{O}_{4} & \boldsymbol{\square} \mathrm{FeO} \quad \star \mathrm{Fe} \quad \bullet \mathrm{ZnFe}_{2} \mathrm{O}_{4} & \boldsymbol{\Delta} \mathrm{Fe}_{2} \mathrm{O}_{3} & \mathrm{OCaCO}_{3} & \square \mathrm{ZnO} & \triangle \mathrm{C}\end{array}$

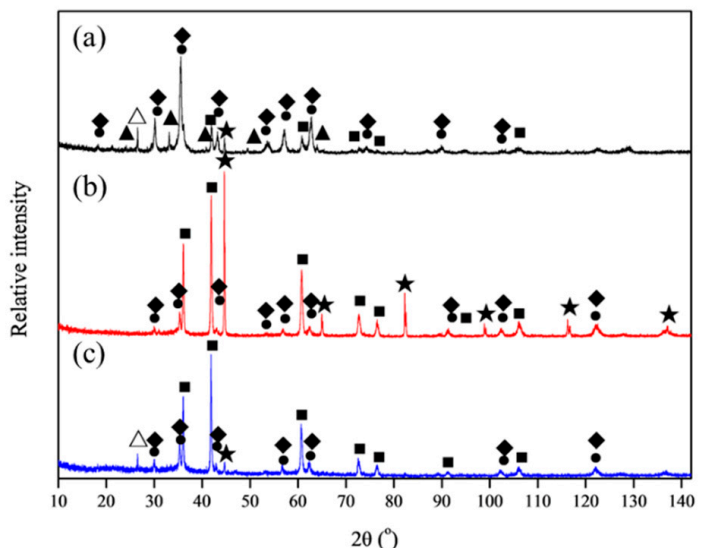

Figure 7. The XRD patterns of the corresponding leaching residues. (a) Residue of BOS-1; (b) Residue of BOS-2; (c) Residue of BOS-3.
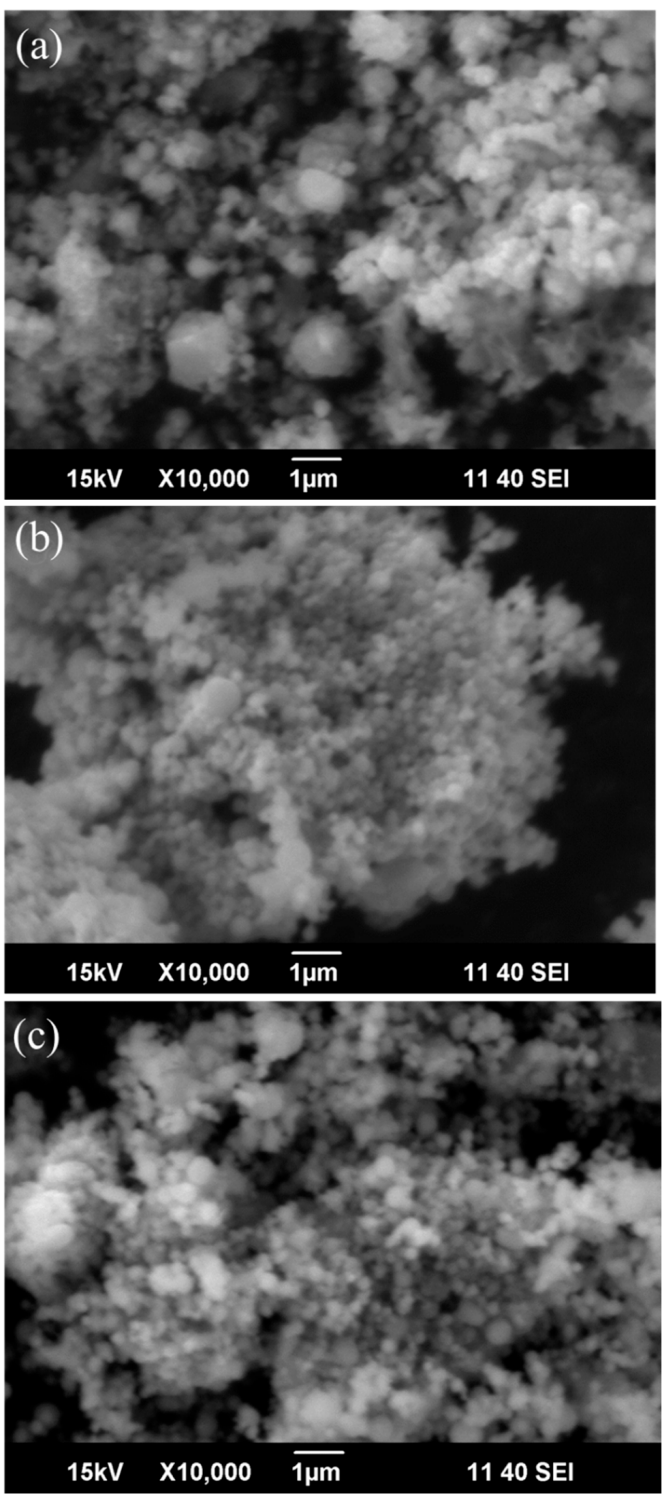

Figure 8. SEM micrographs of the corresponding leaching residues. (a) Residue of BOS-1; (b) Residue of BOS-2; (c) Residue of BOS-3. 


\section{Conclusions}

Selective leaching of zinc over iron from three BOS filter cakes by butyric acid was investigated. The effects of acid concentration and L/S stoichiometric ratio were systematically examined. The following conclusions are obtained:

1. Among the three BOS filter cakes, BOS-3 showed the highest removal of zinc by butyric acid, while the best selectivity of zinc over iron was achieved with BOS-2. The BOS-1 filter cake showed the lowest leaching performance of zinc and iron.

2. The optimal leaching conditions for BOS-3 can be selected depending on the priority consideration. Considering both zinc removal and zinc selectivity, 90\% L/S stoichiometric ratio and $1.0 \mathrm{M}$ acid concentration for $10 \mathrm{~h}$ were chosen as the optimal conditions with $84.6 \%$ zinc removal and $20.0 \%$ iron loss.

3. BOS-1 probably have the self-sinter behavior resulting from long term stockpile with some exothermic oxidation reactions occurred, and those materials generally have stronger physical properties with harder surface, higher density and strength, and larger grain size which can make the acid leaching very difficult. The zinc leaching from BOS-2 was limited by the franklinite but can reach the maximum by increasing the acid concentration.

4. For the leaching behaviors of zinc and iron from the BOS filter cakes using butyric acid, mineral compositions played a more important role than the leaching parameters.

Supplementary Materials: The following are available online at http:/ /www.mdpi.com/2075-4701/9/4/417/s1, Figure S1: Progress of leaching of (a) $\mathrm{Zn}$ and (b) Fe from BOS-3 using $1.0 \mathrm{M}$ butyric acid with different $\mathrm{L} / \mathrm{S}$ stoichiometric ratios, Table S1: The $\mathrm{pH}$ variations obtained from the leachates for the three $\mathrm{BOS}$ filter cakes under different leaching conditions.

Author Contributions: Conceptualization, investigation, writing the manuscript-J.W.; Data analysis, reviewing and editing-Z.W. and G.Z.; Supervision, project administration-G.Z. and Z.Z. All authors have discussed the results, read and approved the final manuscript.

Funding: This research received no external funding.

Acknowledgments: The first author is supported by a University of Wollongong-China Scholarship Council joint scholarships. The authors acknowledge the use of facilities within the UOW Electron Microscopy Centre. Paul Carr and José Abrantes assisted with sample preparation and XRF analysis. Linda Tie assisted in ICP-OES analysis.

Conflicts of Interest: The authors declare no conflict of interest.

\section{References}

1. Yang, S.; Zhao, D.; Jie, Y.; Tang, C.; He, J.; Chen, Y. Hydrometallurgical process for zinc recovery from C.Z.O. Generated by the steelmaking industry with ammonia-ammonium chloride solution. Metals 2019, 9, 83. [CrossRef]

2. Vereš, J.; Jakabský, Š.; Lovás, M. Zinc recovery from iron and steel making wastes by conventional and microwave assisted leaching. Acta Montanistica Slovaca 2011, 16, 185.

3. Jaafar, I. Chlorination for the Removal of Zinc from Basic Oxygen Steelmaking (BOS) by-product. Ph.D. Thesis, Cardiff University, Cardiff, UK, 2014.

4. Vereš, J.; Jakabský, Š.; Lovás, M.; Hredzák, S. Non-isothermal microwave leaching kinetics of zinc removal from basic oxygen furnace dust. Acta Montanistica Slovaca 2010, 15, 204-211.

5. Ma, N. Recycling of basic oxygen furnace steelmaking dust by in-process separation of zinc from the dust. J. Clean. Prod. 2016, 112, 4497-4504. [CrossRef]

6. Cantarino, M.V.; de Carvalho Filho, C.; Mansur, M.B. Selective removal of zinc from basic oxygen furnace sludges. Hydrometallurgy 2012, 111, 124-128. [CrossRef]

7. Kelebek, S.; Yörük, S.; Davis, B. Characterization of basic oxygen furnace dust and zinc removal by acid leaching. Miner. Eng. 2004, 17, 285-291. [CrossRef]

8. Gargul, K.; Boryczko, B. Removal of zinc from dusts and sludges from basic oxygen furnaces in the process of ammoniacal leaching. Arch. Civil Mech. Eng. 2015, 15, 179-187. [CrossRef] 
9. Stefanova, A.; Aromaa, J. Alkaline Leaching of Iron and Steelmaking Dust. Research Report, Aalto University publication series Science + Technology 1/2012. Available online: https://aaltodoc.aalto.fi/ handle/123456789/3570 (accessed on 24 April 2018).

10. Wang, J.; Wang, Z.; Zhang, Z.; Zhang, G. Zinc removal from basic oxygen steelmaking filter cake by leaching with organic acids. Metall. Mater. Trans. B 2019, 50, 480-490. [CrossRef]

11. Trung, Z.H.; Kukurugya, F.; Takacova, Z.; Orac, D.; Laubertova, M.; Miskufova, A.; Havlik, T. Acidic leaching both of zinc and iron from basic oxygen furnace sludge. J. Hazard. Mater. 2011, 192, 1100-1107.

12. Zeydabadi, B.A.; Mowla, D.; Shariat, M.; Kalajahi, J.F. Zinc recovery from blast furnace flue dust. Hydrometallurgy 1997, 47, 113-125. [CrossRef]

13. Jaafar, I.; Griffiths, A.J.; Hopkins, A.; Steer, J.M.; Griffiths, M.H.; Sapsford, D.J. An evaluation of chlorination for the removal of zinc from steelmaking dusts. Miner. Eng. 2011, 24, 1028-1030. [CrossRef]

14. Sofilić, T.; Rastovčan-Mioč, A.; Cerjan-Stefanović, Š.; Novosel-Radović, V.; Jenko, M. Characterization of steel mill electric-arc furnace dust. J. Hazard. Mater. 2004, 109, 59-70. [CrossRef]

15. Bakkar, A. Recycling of electric arc furnace dust through dissolution in deep eutectic ionic liquids and electrowinning. J. Hazard. Mater. 2014, 280, 191-199. [CrossRef]

16. Gargul, K.; Jarosz, P.; Malecki, S. Alkaline leaching of low zinc content iron-bearing sludges. Arch. Metall. Mater. 2016, 61, 43-50. [CrossRef]

17. Aromaa, J.; Kekki, A.; Stefanova, A.; Makkonen, H.; Forsén, O. New hydrometallurgical approaches for stainless steel dust treatment. Miner. Process. Extr. Metall. 2016, 125, 242-252. [CrossRef]

18. Miki, T.; Chairaksa-Fujimoto, R.; Maruyama, K.; Nagasaka, T. Hydrometallurgical extraction of zinc from $\mathrm{CaO}$ treated EAF dust in ammonium chloride solution. J. Hazard. Mater. 2016, 302, 90-96. [CrossRef]

19. Palimąka, P.; Pietrzyk, S.; Stępień, M.; Ciećko, K.; Nejman, I. Zinc recovery from steelmaking dust by hydrometallurgical methods. Metals 2018, 8, 547. [CrossRef]

20. Langová, Š.; Leško, J.; Matýsek, D. Selective leaching of zinc from zinc ferrite with hydrochloric acid. Hydrometallurgy 2009, 95, 179-182. [CrossRef]

21. Steer, J.M.; Griffiths, A.J. Investigation of carboxylic acids and non-aqueous solvents for the selective leaching of zinc from blast furnace dust slurry. Hydrometallurgy 2013, 140, 34-41. [CrossRef]

22. Vereš, J.; Jakabský, Š.; Lovás, M. Comparison of conventional and microwave assisted leaching of zinc from the basic oxygen furnace dust. Miner. Slovaca 2010, 42, 369-374.

23. Wang, J.; Wang, Z.; Zhang, Z.; Zhang, G. Removal of zinc from basic oxygen steelmaking filter cake by selective leaching with butyric acid. J. Clean. Prod. 2019, 209, 1-9. [CrossRef]

24. Mikhail, S.A.; Turcotte, A.-M. Thermal reduction of steel-making secondary materials: I. Basic-oxygenfurnace dust. Thermochim. Acta 1998, 311, 113-119. [CrossRef]

25. Longbottom, R.J.; Monaghan, B.J.; Zhang, G.; Chew, S.J.; Pinson, D.J. Characterisation of steelplant by-products to realise the value of Fe and Zn. In Proceedings of the 7th European Coke and Ironmaking Congress (ASME 2016), Linz, Austria, 12-14 September 2016.

(C) 2019 by the authors. Licensee MDPI, Basel, Switzerland. This article is an open access article distributed under the terms and conditions of the Creative Commons Attribution (CC BY) license (http://creativecommons.org/licenses/by/4.0/). 